\title{
Comprehensive analysis of small RNA profile by massive parallel sequencing in HTLV-1 asymptomatic subjects with monoclonal and polyclonal rearrangement of the $T$-cell antigen receptor $\gamma$-chain
}

Daniela Raguer Valadão de Souza ${ }^{1 \$}$, Rodrigo Pessôa ${ }^{1 \$}$, Youko Nukui $^{2}$, Juliana Pereira ${ }^{2}$, Jorge Casseb ${ }^{1}$, Augusto César Penalva de Oliveira ${ }^{3}$, Patricia Bianca Clissa ${ }^{4}$, Sabri Saeed Sanabani ${ }^{1 *}$

${ }^{1}$ Laboratory of Dermatology and Immunodeficiency, São Paulo University Medical School, Sao Paulo, SP, Brazil.

${ }^{2}$ Departments of Hematology, Faculty of Medicine, University of São Paulo, São Paulo, Brazil.

${ }^{3}$ Institute of Infectious Diseases "Emilio Ribas" (IIER), São Paulo, São Paulo, BraziL.

${ }^{4}$ Immunopathology Laboratory, Butantan Institute, Sao Paulo-SP, Brazil

* Corresponding author

Sabri Saeed Sanabani, PhD

E-mail: sabyem_63@yahoo.com

Laboratory of Dermatology and Immunodeficiency, LIM56/03.

Instituto de Medicina Tropical de São Paulo

Faculdade de Medicina da Universidade de São Paulo

Av. Dr. Eneas de Carvalho Aguiar, $4703^{\circ}$ andar

São Paulo Brazil 05403000

Phone: + 551130617194 ext:218

\$These authors contributed equally to this work

Running title: small RNA profile in HTLV-1 asymptomatic subjects

Abbreviations: sRNA: small RNA, miRNA: microRNA, ncRNA: non-coding RNA tRNA: transfer RNA, rRNA: ribosomal RNA, snRNA : small nuclear RNA, snoRNA : small nucleolar RNA, scRNA: small cytoplasmic RNA, PBMC: peripheral blood mononuclear cell, HTLV-I: Human T-lymphotropic virus type I, ASM: asymptomatic monoclonal, ASP: asymptomatic polyclonal, ATLL: adult T-cell leukemia/lymphoma

Keywords: small RNA, HTLV-1, T-cell antigen receptor, asymptomatic carriers, massive parallel sequencing 


\section{Abstract}

\section{Introduction}

In this study, we used a massive parallel sequencing technology to investigate the cellular small RNA (sRNA) operating in peripheral blood mononuclear cells (PBMCs) of the Human T-lymphotropic virus type I (HTLV-I) infected asymptomatic subjects with a monoclonal and polyclonal rearrangement of the T-cell antigen receptor $\gamma$-chain.

\section{Materials and Methods}

Blood samples from 15 HTLV-1 asymptomatic carriers who were tested for clonal $T C R-\gamma$ gene (seven and eight subjects presented monoclonal and polyclonal expansion of HTLV-1 infected cells, respectively), and were submitted to Illumina for small RNA library construction. sRNA libraries were prepared from cryoperserved PBMCs using TrueSeq Small RNA Library Preparation Kit (Illumina). The sRNA-Seq reads were aligned, annotated, and profiled by different bioinformatics tools.

\section{Results}

Through bioinformatics analysis, we identified a total of 494 known sRNAs and 120 putative novel sRNAs. Twenty-two known and 15 novel sRNA showed a different expression (>2-fold) between the asymptomatic monoclonal (ASM) and asymptomatic polyclonal carriers (ASP). The hsa-mir-196a-5p was the most abundantly upregulated micro RNA (miRNA) and the hsa-mir-133a followed by hsa-mir-509-3p were significantly downregulated miRNAs with more than a three-fold difference in the ASM than ASP group. The target genes predicted to be regulated by the differentially expressed miRNAs play essential roles in diverse biological processes including cell proliferation, differentiation, and/or apoptosis. 
bioRxiv preprint doi: https://doi.org/10.1101/277871; this version posted March 7, 2018. The copyright holder for this preprint (which was not certified by peer review) is the author/funder. All rights reserved. No reuse allowed without permission.

\section{Discussion}

Our results provide an opportunity for a further understanding of sRNA regulation and function in HTLV-1 infected subjects with monoclonality evidence. 


\section{Introduction}

Human T-lymphotropic virus type I (HTLV-I) is an oncogenic human retrovirus that was first isolated from a T-cell line, HUT102, that had been obtained from a patient with adult T-cell leukemia/lymphoma (ATLL) [1]. Globally, there are an estimated 5-10 million individuals who carry the HTLV-I, with the important caveat that the prevalence remains barely unknown in many areas of the world [2]. The disease burden is unevenly distributed, with a higher incidence of the disease particularly in southwest Japan, the Caribbean islands, South America, and portions of Central Africa [3]. Infection with HTLV-I may result in a spectrum of clinical manifestations, ranging from asymptomatic infection to a number of human disorders, most notably a malignant ATLL and a chronic progressive neuromyelopathy, termed HTLV-I-associated myelopathy/tropical spastic paraparesis (HAM/TSP) [4]. The majority of HTLV-I-infected individuals remain asymptomatic for life, while some individuals progress to a pre-leukemic phase that is characterized by small numbers of circulating leukemic cells in the peripheral blood, skin lesions, and a lack of involvement of other organ systems [5]. Only $2.5 \%$ to $5 \%$ of the virus carriers eventually develop ATLL after a long asymptomatic period [6, 7]. The reason why some people develop the disease, whereas others remain healthy, is likely dependent on both host-related and virus-related factors [8]. Available evidence from molecular studies indicates that the impairment of various cellular functions by viral genes (e.g., tax and $H B Z$ ), genetic and epigenetic changes including DNA methylation, and the host immune system may contribute to the leukemogenesis of ATLL [9-11]. Despite the effective immortalization of the $\mathrm{T}$ cells, the markedly prolonged incubation period (>30 years) prior to the onset of ATLL, suggests an additional acquisition of genetic changes beside the viral infection to contribute to the pathogenesis [12]. 
Infections with HTLV-1 are expected to produce an initial polyclonal T-cell proliferation followed by a monoclonal malignant transformation in asymptomatic HTLV-1 carriers before the diagnosis of Adult T-cell Leukaemia/Lymphoma becomes evident. HTLV-1carriers who have monoclonal integration of HTLV-1 provirus DNA in their mononuclear cells are suggested to be a high-risk group for development of ATLL, but their prognosis varies from being stable long-term carriers to experiencing the development of ATLL [13-16]. Carvalho and Da Fonseca Porto [17] also found a correlation between monoclonal integration of provirus DNA and abnormal lymphocytes in peripheral blood, with a trend for greater severity of the parasitic infection.

Over the past several years, some studies have provided significant evidence to support transcription of many non-protein-coding regions of the mammalian genome [18], yielding a complex network of transcripts that include tremendous numbers of noncoding RNAs (ncRNA). These molecules play significant roles in normal biological processes and in a variety of human diseases [19]. Within this diverse menagerie of ncRNA, small RNAs (sRNAs), have emerged as potential posttranscriptional regulators of gene expression in both eukaryotes and prokaryotes [20]. Because these molecules are highly complex in terms of structural diversity and function, their families have been grouped into structural and regulatory ncRNA [21]. The structural ncRNA includes transfer RNA (tRNA) and ribosomal RNA (rRNA), as well as other small but stable noncoding RNAs, such as small nuclear RNAs (snRNAs), small nucleolar RNAs (snoRNAs), small cytoplasmic RNA (scRNA), Ribonuclease P (RNase P), mitochondrial RNA processing (MRP) RNA, signal recognition particle (SRP) RNA, and telomerase RNA. Regulatory ncRNAs include microRNAs (miRNAs), PIWIinteracting RNAs (piRNAs), and long ncRNAs (lncRNAs) [22]. The miRNAs are 
perhaps the single best-understood subclass. They are typically $18-25$ nucleotides (nt) in length, single-stranded RNAs that have emerged as principal post-transcriptional regulators of gene expression and play a vital role in several cell processes including cell proliferation, differentiation, apoptosis, embryonic development, and tissue differentiation [23, 24]. The mature molecules of miRNAs are assembled into ribonucleoprotein complexes called miRNA-induced silencing complexes (RISC), which inhibits gene expression by perfect complementary binding, for mRNA degradation, or imperfect binding at the 3'UTR region, to inhibit translation[25]. The rigid control of miRNA expression is critically important to maintain cells in normal physiological states [26], while overexpression of miRNAs has been associated with the occurrence and development of various diseases [25, 27]. It has been proven that oncogenic (onco-miRs) and tumor-suppressor (TS-miRs) miRNAs exert control over important cell cycle components and thus results in either acceleration or deceleration of the cell cycle [28-30].

In theory, dysregulation of host cells miRNAs by HTLV-1 might influence the development of ATLL. Indeed, some reports attest to the critical role of cellular miRNA to proliferation and survival of HTLV-1-infected T-cells. Hybridization-based methodologies, such as microarray and PCR-based assays have been used thus far to identify and profile the cellular miRNAs in HTLV-1 infected cell lines [31, 32]. The study by Pichler et al. [33], who first used quantitative PCR to study the interconnections between HTLV-1 and cellular miRNAs, confirmed that HTLV-1 transforms host cells by inducing dysregulation of the expression of specific miRNAs, including miR-146a, which is upregulated by Tax protein (an oncoprotein of HTLV-1). Subsequently, other expression studies revealed both up- and downregulation in a number of miRNAs in HTLV-1/ATLL cell lines and primary ATLL cells $[34,35]$. 
Recently, Ruggero and colleagues [36] employed massive sequencing to identify the repertoire of microRNAs and tRNA fragments (tRFs) expressed in HTLV-1-infected cells compared to normal CD4+ T cells. Most of the previous studies mainly focused on expression of specific or diverse miRNA in HTLV-1 infected cell lines, while few studies have focused on determining the expression profiles of sRNAs isolated from human blood samples. Thus, it would be clinically relevant to investigate early gene regulatory mechanisms associated with cell transformation in HTLV-1 asymptomatic patients with monoclonal expansion features.

In this study, we employed Illumina massive parallel sequencing technology to comprehensively characterize the sRNA expression profiles in the peripheral blood mononuclear cells (PBMCs) of HTLV-1 infected asymptomatic subjects with monoclonal (ASM) and polyclonal (ASP) T cell expansions. Our results revealed 494 known sRNAs and 120 putative novel sRNAs. Moreover, 23 known and 15 novel sRNA showed different expressions (>2-fold) between the ASM and the ASP groups. The data obtained in this study provides considerable insight into understanding the expression characteristic of sRNAs in HTLV-1 carriers with monoclonal $\mathrm{T}$ cell population. Differentially expressed sRNAs described here may be associated with the transformation of T cells. 


\section{Materials and Methods}

\section{Patients' characteristics and sample preparations}

Peripheral blood samples were initially collected from a relatively large group of asymptomatic HTLV-1 carriers $(\mathrm{n}=367)$. Of these subjects, 15 carriers were selected for this study on the basis of clonality results and classified to ASM $(n=7)$ and ASP $(n=8)$. The samples were collected after approval by the institutional health research ethic authority and the signing of written informed was obtained from all individual participants included in the study. Isolation of PBMCs was carried out by FicollHypaque (Amersham, Upsala, Sweden) density centrifugation, washed twice in RPMI 1640 with $10 \%$ fetal calf serum, and stored in liquid nitrogen until use. A summary of the clinical characteristics of study subjects is shown in Table $\mathbf{1 .}$

\section{Genomic DNA and RNA extraction}

Genomic DNA was extracted from PBMCs using the QIAamp blood kit (QIAGEN, Tokyo, Japan). The miRNeasy Mini Kit (Qiagen, Hilden, Germany) in conjunction with the TRIzol (Life Technologies, USA) procedure were used to extract total RNA and sRNA following the manufacturer's protocols. Briefly, $700 \mu \mathrm{L}$ of TRIzol was added to $200 \mu \mathrm{L}$ of cryoperserved PBMCs followed by incubation at room temperature for $5 \mathrm{~min}$. Chloroform (Sigma-Aldrich, St. Louis, MO, USA) was added, and the samples were vortexed and incubated at room temperature for $5 \mathrm{~min}$ followed by centrifugation at $12,000 \times g$ for $15 \mathrm{~min}$ at $4^{\circ} \mathrm{C}$. The aqueous phase containing RNA was transferred to a new tube and isopropanol (Fisher-Scientific, Thermo Fisher Scientific, Waltham, MA, USA) was added. The samples were incubated at room temperature for $10 \mathrm{~min}$ followed by centrifugation at $12,000 \mathrm{xg}$ for $15 \mathrm{~min}$ at $4^{\circ} \mathrm{C}$. The pellet was washed with $75 \%$ Ethanol (Sigma-Aldrich), air-dried, and resuspended in $20 \mu \mathrm{L}$ nuclease-free water 
(Ambion). For addition of carriers, $2 \mu \mathrm{L}$ of glycogen $(5 \mu \mathrm{g} / \mu \mathrm{L})$ was added during the isopropanol precipitation step. For the miRNeasy Mini Kit, the aqueous phase was added to 1.5 volumes of $100 \%$ ethanol, and the mixture was mixed thoroughly by pipetting. The supernatants were then transferred to the miRNeasy Mini spin column by centrifugation. Thereafter, the column was washed with $700 \mu \mathrm{l}$ of RWT, $500 \mu \mathrm{l}$ of RPE, and $500 \mu \mathrm{l}$ of $80 \%$ ethanol, and then dried by centrifugation at $12000 \times g$ for $5 \mathrm{~min}$. Finally, the sRNAs on the membrane were eluted in $22 \mu \mathrm{l}$ of RNase-free water and stored at $-80^{\circ} \mathrm{C}$ until further use.

\section{Concentration measurement of genetic materials}

Both DNA and RNA including sRNA concentration measurements by fluorimetry were done on Qubit 2.0 fluorometer using Qubit® DNA or RNA HS Assay Kit (Thermo Fisher Scientific), respectively. Briefly, $10 \mu \mathrm{L}$ standards or diluted genetic materials were mixed with Qubit@ Working Solution and incubated for 2 min. Two standards were prepared, one has $0 \mathrm{ng} / \mu \mathrm{L}$ and the other has $10 \mathrm{ng} / \mu \mathrm{L}$ concentrations. To obtain the calibration curve, the relative fluorescence was plotted against the concentrations of the two standards. The fluorometer built-in software was used to compute the concentration values of the genetic materials of each sample.

\section{HTLV-1 proviral load determination}

The extracted DNA was used as a template to amplify a 97-bp fragment from the HTLV-1 tax region using previously published primers [37] and protocol [38]. Amplification and analysis were performed with the Applied Biosystems 7500 real-time PCR system. The standard curves for HTLV-1 tax were generated from MT-2 cells of $\log _{10}$ dilutions (from $10^{5}$ to $10^{0}$ copies). The threshold cycle for each clinical sample was calculated by defining the point at which the fluorescence exceeded a threshold limit. Each sample was assayed in duplicate, and the mean of the two values was 
considered the copy number of the sample. The HTLV-1 proviral load was calculated as the copy number of HTLV-1 (tax) per 1000 cells $\square=\square$ (copy number of HTLV-1 tax)/(copy number of $R$ Nase $P$ gene/2) $\times 1000$ cells. The method could detect one copy per $10^{3}$ PBMCs.

\section{Analysis of T cell receptor yTCR genes}

A DNA-based polymerase chain reaction (PCR) of rearranged yTCR genes was performed according to the previously described protocol [39]. All patients' PCR products were analyzed with the 3130 ABI Prism capillary electrophoresis equipment. $0.5 \mu \mathrm{ROX}, 13 \mu \mathrm{l} \mathrm{Hidi}$, and $1 \mu \mathrm{l}$ template DNA sample were added to each well in a 96well plate. Data were analyzed using Genescan and Genotyper software (Applied Biosystem, Foster City, CA). T cell clonalities were blindly determined by visual examination of the electropherograms by two analysts and further confirmed by an expert hematology pathologist (coauthor JP).

sRNA construction and massive parallel sequencing (MPS)

For each sample in both groups, sRNA libraries were prepared with the Small RNA v1.5 sample preparation kit as per the manufacturer's instructions (Illumina, San Diego, CA) and previous protocol [40]. Briefly, $5 \mu$ l of purified total RNAs were ligated with $1 \mu$ RNA 3' Adapter and then with a 5' RNA adapter (Illumina, San Diego, CA). The 5' adapter also included the sequencing primer. After RT-PCR amplification, the resulting products were analyzed using polyacrylamide gel electrophoresis (PAGE) (6\% Novex Tris-borate-EDTA [TBE] PAGE; Invitrogen). After gel electrophoresis, sRNA bands at sizes $145-150 \mathrm{bp}$ were excised and purified. Finally, each four libraries were pooled and up to $8-10 \mathrm{pM}$ of the pooled libraries were loaded and sequenced on the MiSeq platform (Illumina) with a 36 base single-end protocol, according to the manufacturer's instructions. 


\section{SRNA Data analysis and interpretation}

Base calling, demultiplexing, and trimmed FASTQ files were generated using the MiSeq reporter. Only high quality reads with score $>30$ on the Sanger scale were considered for further analysis. The reads were aligned against the whole genome build: hg19 using Strand NGS v3.1. The later software package was also used for analysis of novel molecule discoveries and interpretations. The distributions of the sRNA data in each clinical condition were conducted according to the quantile normalization algorithm, with a baseline transformation set to the median of all samples. Novel sRNA were discovered and classified by the decision tree method with three-fold validation accuracy using model previously described by Langenberger et al. [41]. Additionally, only sRNA sequences meeting the minimum read coverage criterion of $>20$ were considered as novel or known sRNA and were included in further analyses. sRNAs with fold change more than 2.0 were considered to be differentially expressed. All the sRNA raw data generated by MPS has been deposited to the Zenodo repository.

\section{Functional annotation and pathway analysis of miRNA target genes}

The target genes from differentially expressed miRNAs were predicted by PicTar, TarBase microRNAorg databases. Pathway analysis was carried out for a functional analysis of mapping genes to KEGG pathways [42]. Prediction was performed by using DIANA-microT-CDS [43]. The biological functions of these target genes were determined by the enriched GO analysis (false discovery rate $p$-value $<0.05$ ). 


\section{Results}

\section{Patient Characteristics}

The characteristics of the subjects in both groups are shown in Table 1. All eight participants within the ASP group were female and the median age was 58 years (range, 31-80 years). Six females and one male were assigned to the ASM group and the median age of the entire group of subjects was 61 years (range, 28-74 years). HTLV-1 proviral load levels varied from one copy to 208 copies $/ 10^{3}$ PBMCs in the ASP group and varied from undetectable to 327 copies $/ 10^{3}$ PBMCs in the ASM group (two-tailed $P$ value $=0.7)$

\section{Description of whole genome sRNA-sequencing data from both groups}

Illumina MPS revealed a total of $130,415,317$ reads. After removal of low quality data and reads that failed vendor`s QC, 125,435,316 reads were retained. The filtered sRNA reads on quality metrics for each sample used in the alignment to the human genome sequence dataset are shown in Table 1. For instance, sample 131 within the ASP group had 3,779,138 filtered sRNA reads out of 3,944,199 of raw reads and sample 143 in the ASM group displayed 5,472,836 of filtered sRNA reads out of 5,719,645 raw reads. We next investigated the percentage of reads assigned to abundant sRNA categories or sRNA biotypes (Figure 1, representative for samples 131 and 143). More than 69\% and $59 \%$ of the reads in samples 131 and 143, respectively, matched to mature miRNA. The rest of the sequences were matched into other types of sRNAs including intronic RNAs, exonic RNAs, scRNAs, snRNAs, snoRNAs, tRNAs, and others. Next, we evaluated the location of these tags on the chromosome. In the majority of samples from both groups, most of the unique tags were located on chromosome 3, 8, 12, and 19 (table S1). The Illumina MPS yielded 614 sRNA molecules, of which 494 sequences were derived from known sRNA, and 120 were novel sRNA. Of the 494 known sRNA, 219 were miRNA, 
30 scRNA, 9 scRNA_pseudogene, 162 snoRNA, 23 snRNA, and 51 tRNA (table S2).

Of the 120 novel genes, 25 were novel miRNA, 50 snoRNA, 3 snRNA, 9 tRNA, and 33 unknown (table S3). Considering $-3 p$ and $-5 p$ mature forms of miRNA, our analysis revealed a total of 2104 mature miRNA, of which 22 had had greater than a two-fold change in expression (table 2).

\section{Characteristics of the abundant known and novel sRNAs}

Among the 494 known sRNAs identified in this study, 52 sRNAs were found to be differentially expressed (>2-fold) between the ASM group and ASP group, which accounted for $8.5 \%(52 / 614)$ of all the sRNAs investigated (table S4). Clustering by group was not noted in the hierarchal combined tree of the 52 significantly differentially expressed sRNA levels as shown in figure 2. Of these 52 sRNAs, 50 were upregulated and two were downregulated in the ASM group. The upregulated sRNA includes three miRNA, 10 scRNA, one scRNA_pseudogene, 21 snoRNA, one snRNA, and 14 tRNA. On the other hand, the down-regulated entities include only two miRNA. Of the highly expressed sRNAs, SNORD45, SNORD45B, hsa-mir-196a-1, hsa-mir-196a-2, and SCARNA5 were the top five most abundantly expressed sRNA in PBMCs of the ASM group, among which, SNORD45 had greater than 5.7 fold changes in expression (table S4). The most abundantly downregulated sRNAs in PBMCs of the ASM group were hsa-mir-133a-1 and hsa-mir-133a-2, which showed more than 3.8 fold changes in the ASM when compared to the ASP group (table S4). Further, of the 22 mature miRNAs that exhibited a $>2$-fold difference in expression in the PBMCs of the ASM compared to the ASP group, 11 miRNAs were upregulated and 11 were downregulated (table 2). The hierarchical clustering analysis of these miRNAs showed distinct patterns of miRNA expression levels between ASM and ASP groups (Figure 3). The hsa-mir196a-5p was the most abundantly upregulated miRNA and the hsa-mir-133a followed 
by hsa-mir-509-3p were the significantly downregulated miRNAs with more than a three-fold difference in the ASM than the ASP group. Of the 120 novel sRNA described in this study and shown in table $\mathbf{S 3}, 15$ were found to be differentially expressed ( $>2$ fold) between the ASM group and ASP group, which accounted for $2.4 \%$ of all the sRNAs investigated. Of these, 14 were upregulated and one was downregulated in the PBMCs of the ASM group when compared to the ASP group. Of the upregulated novel sRNAs, four were snoRNA, one miRNA, one tRNA, and eight were unknown while the unique downregulated gene was snoRNA (Table 3).

\section{GO Analysis of the Target Genes of the Differentially Expressed sRNAs}

The role of a miRNA is ultimately defined by the genes that it targets and by its effect on the expression of those genes. To discover these functions, the target genes of the two groups of the mature significantly expressed miRNAs were predicted using the three programs PicTar, TarBase, and microRNAorg databases. The intersection of these three programs was used to reduce the false-positive rate. As shown in Table S5, a $p$ value cutoff of 0.001 was selected to predict nine target genes. The most significantly selected candidate target gene FGD6 is regulated by 13 of the 27 mature significantly expressed miRNAs. The second most selected target gene is the CUGBP Elav-like family member 6 (CELF6) gene, which is regulated by 10 of the 27 mature significantly expressed miRNAs. To identify the actual regulatory functions of the miRNAs, the GO annotation of the target genes was performed on the list of predicted target miRNAs that corresponded with altered miRNAs in the ASM group at $\mathrm{p}$ value $<0.05$. The results from this analysis revealed no significant GO enrichments for the differentially expressed genes predicted from the known miRNAs. The Kyoto Encyclopedia of Genes and Genomes (KEGG) pathways of target genes were assigned using mirPath v.3 in DIANA tools webserver. KEGG pathway annotation revealed that 3044 background 
genes were annotated for 56 biological functions. The top five pathways were Adherens

junction, Proteoglycans in cancer, Axon guidance, Morphine addiction, and Prion diseases. 


\section{Discussion}

In this study, we used Illumina high-throughput sequencing technology to analyse the global expression of non-coding RNome in PBMCs of HTLV-1 infected asymptomatic subjects with monoclonal and polyclonal rearrangement of the T-cell antigen receptor $\gamma$ chain. Our results revealed 52 significantly differentially expressed sRNAs in the ASM group compared with the ASP subjects. Furthermore, we identified 15 novel sRNA exhibited much higher expression levels in ASM patients than reads in ASP. Eleven of the 22 differentially expressed mature miRNA were up-regulated while the other 11 were down-regulated in the ASM group. Out of the 22 most dysregulated miRs, we selected the most significantly up-regulated miRs (miR-196a-5p) and down-regulated miRs (miR-133a, miR-625-3p, and miR-3120-3p) assuming that the measurement of these miRs could discriminate ASM from ASP patients and that the dysregulation of these miRs in ASM may represent early markers for $\mathrm{T}$ cell transformation with unknown functional consequences.

We searched for putative target genes associated with enhancement of cellular transformation. The upregulation of miR-196a, located in HOX gene clusters [44], has been suggested to potentially target HOXB8, HOXC8, HOXD8 and HOXA7 [45]. HOX proteins consist of homeodomain-containing transcription factors that are primary determinants of cell fate during embryogenesis, organogenesis, and oncogenesis [46]. Reports from previous studies have proved that upregulation of miR-196a promotes cell proliferation, anchorage-independent growth, and suppressed apoptosis by targeting annexin A1 [47]. Although most studies proved that over expressed miR-196a is associated with oncogenic function in various types of cancers including pancreatic cancer [48], and oesophageal adenocarcinoma [49] but it has been suggested to play a 
tumor suppressive role as well. For instance, Li et al. [50] have demonstrated a potential role of the up-regulated miR-196a in reducing in vitro invasion and in vivo spontaneous metastasis of breast cancer cells. Also, miR-196 has been previously demonstrated to play diverse biological functions involving immune response, inflammation, and virus defense [51]. It was also suggested that upregulation of miR-196a may be used in a novel strategy to prevent or treat hepatitis caused by $\mathrm{C}$ virus infection, and miR-196a may be valuable in the diagnosis and management of this disease $[52,53]$. In relation to T cell leukemia, Coskun and colleagues [54] have shown that miR-196a and miR-196b are regulators of the oncogenic erythroblast transformation-specific (ETS) transcription factors of the ETS related genes (ERG). The ERG plays important physiological and oncogenic roles in hematopoiesis [55]. It is also a prognostic factor in a subset of adult patients with acute T cell leukemia [56]. Coskun and colleagues [54] provided evidence that both miR-196a and miR-196b expression were linked to immature immunophenotype (CD34 positive) in ATLL patients. These findings indicate miR196a and miR-196b as ERG regulators and have potential implications in ATLL. Based on the above facts, we therefore assumed that the aberrant expression of miR-196a might contribute to the development and transformation of HTLV 1 infected cells in the ASM group.

The miR-133a (known to control HLA-G protein stability) is one of the canonical myomiRs that at the crossroads of the molecular of muscle cells, connecting between pathways for cell differentiation, development and maintenance, but also potentiates aberrant cell growth in a wide range of non-muscle cancers [57]. miR-133 was predicted to bind to both $\mathrm{N}$ and $\mathrm{G}$ transcripts of rabies viruses and this interaction possibly explains the lengthy dormant state of this virus in skeletal muscles during the early phase of infection $[58,59]$. In a recent study, the expression change of miR-133a has 
been shown to negatively affect the replication of dengue viruses when overexpressed in mammalian cells [60]. The deregulation of miR-133a has been reported in many tumor types of distinct origin, including ovarian [61], prostate [62], bladder [63], and head and neck squamous cell cancer [64]. In most of these cancers, the miR-133a together with other miRs is associated with negative regulation of Fascin. The latter is a global protein that is strongly upregulated in ATLL-derived cells and in CD4+ T-cells transformed by HTLV-1 or by the viral oncoprotein Tax [65]. The loss of miR-133a expression was also associated with a poor survival of tumor patients [66]. The downregulated miR-133a together with dysregulation of other documented miRs in this study was positively and significantly correlated with some predicted potential target genes including the CUG-binding protein and embryonic lethal abnormal vision-type RNAbinding protein 3-like factor 6 (CELF6), calcium/calmodulin-dependent serine protein kinase interacting protein 2 (CASKIN2), exportin 1 (XPO1), and the solute carrier family 33 member 1 (SLC33A1). The CELF6 protein is an important regulator of cellspecific alternative splicing during normal development and disease [67]. Altered expression of CELF6 has been associated with renal disorders and body weight changes $[68,69]$. CASKIN2 is a neuronal signaling scaffolding protein involved in signaling neuronal synapses. In vitro experiments revealed that overexpression of Caskin2 inhibits serum-induced endothelial cells (EC), proliferation, and DNA synthesis but promotes EC survival during serum starvation, thus suggesting a role of this protein in preventing EC dysfunction in vivo [70]. The human chromosomal maintenance 1 or XPO1 mediates the nuclear export of cellular proteins (cargos) bearing a leucine-rich nuclear export signal) and of RNAs. Various viruses, among them HIV-1, HTLV-1 and influenza A use it to export their unspliced or incompletely spliced RNAs out of the nucleus. The XPO1 interacts with, and mediates the nuclear export of HTLV-1 Rex 
proteins and critically needs it for its multimerization $[71,72]$. The SLC33A1 is an important substrate for a large variety of biochemical reactions occurring in the cell [73].

The search for the putative target RNA molecules in the database showed that miR-625$3 p$ can potentially target the gene that codes for the clathrin heavy chain (CLTC) protein. Clathrin is the major protein component of the coat that surrounds the cytoplasmic face of the organelles (coated vesicles) mediating selective protein transport [74]. Clathrin coats play an essential role in receptor-mediated endocytosis, localization of resident membrane proteins to the compartments within the trans-Golgi network, and transport of proteins to the lysosome/vacuole $[75,76]$. The clathrin coats contain both clathrin and four adaptor complexes (APs 1-4), which participate in the selection of protein cargo and their incorporation into clathrin-coated transport vesicles [77]. Previous studies showed that AP-2 and AP-3 interact with HIV-1 Gag and contribute to its trafficking and release $[78,79]$ and that the disruption of this interaction enhances viral release, while reducing the infectivity of the virions produced [78]. Camus and colleagues, 2007 [80] propose that in HIV-1 and murine leukemia virus, the AP-1 promotes Gag release by transporting it to intracellular sites of active budding, and/or by facilitating its interactions with other cellular partners. The same study concluded that this interaction is conserved among different retroviruses including HTLV and RSV and suggested that AP-1 could also play a role in the assembly of these retroviruses. In human disease, the few available data indicate that the abnormalities and dysregulation of CLTC are associated with large B-cell lymphoma [81], inflammatory myofibroblastic tumor [82], and multinodular goiter pathogenesis [83].

miR-3120-3p was down-regulated (fold change $=-3.154$ ) in the ASM group, and was negatively correlated with diverse putative target genes such as the SLC33A1, tripartite 
motif containing 27 (TRIM27), XPO1, CASKIN2, and CELF6. The TRIM27 is a member of a large family of proteins that function as Really Interesting New Gene [82] E3 ubiquitin ligases. The TRIM27 has the ability to inhibit the class II phosphatidylinositol 3 kinase $\mathrm{C} 2 \beta$ activity, resulting in decreased KCa3.1 channel activity and decreased TCR-stimulated $\mathrm{Ca} 2+$ influx and cytokine production, thereby identifying TRIM27 as a unique negative regulator of CD4 T cells [84].

There are few microarrays studies that have also characterized the miRNA expression profiles in HTLV-1/ATLL cell lines and ATLL patients [33-35, 85]; however, it is difficult to compare their results with our study due to the different methods employed, different research designs, and different target population.

Our study has several limitations, particularly its retrospective design, and lack of a control non-infected group. Additionally, few samples were included, and no validation study was performed. In spite of these caveats, the current study unravels a number of known and novel subsets of dysregulated sRNA including signature in the PBMCs of the ASM group. The aberrant expression of sRNAs paves the way for assessment of their mechanistic roles and clinical utilities as biomarkers, prognostic indicators, and/or therapeutic targets in early HTLV-1 pathogenesis.

In conclusion, significantly differentially expressed sRNAs including miRNAs and their target genes between ASM and ASP were identified by means of MPS technique. These newly identified miRNAs and target could have unexplored functions in HTLV-1 pathogenesis. Therefore, further investigation of a large population of leukaemia patients using well-matched control groups and sequential samples will be required to elucidate the possible pathogenic impact of these ncRNA molecules in HTLV-1 infection. 


\section{Acknowledgements}

This study was funded by the Fundação de Amparo à Pesquisa do Estado de São Paulo (grants 2011/12297-2 and 2014/24596-2)

\section{Conflict of Interest}

The authors declare that they have no conflict of interest.

\section{Author Contributions}

Conceived and designed the experiments: SSS. Performed the experiments: DRVS, RP, SSS. Analyzed the data: DRVS, RP, PBC, SSS. Contributed reagents/materials/analysis tools: YN JP. Wrote the paper: PBC,SSS. Attending physician for sample collection: YN JP JK ACS. 


\section{References}

1. Poiesz BJ, Ruscetti FW, Gazdar AF, Bunn PA, Minna JD, Gallo RC: Detection and isolation of type $C$ retrovirus particles from fresh and cultured lymphocytes of a patient with cutaneous T-cell lymphoma. Proc Natl Acad Sci U S A 1980, 77(12):7415-7419.

2. Gessain A, Cassar O: Epidemiological Aspects and World Distribution of HTLV-1 Infection. Front Microbiol 2012, 3:388.

3. Matsuoka M: Human T-cell leukemia virus type I and adult T-cell leukemia. Oncogene 2003, 22(33):5131-5140.

4. Verdonck K, Gonzalez E, Van Dooren S, Vandamme AM, Vanham G, Gotuzzo E: Human T-lymphotropic virus 1: recent knowledge about an ancient infection. Lancet Infect Dis 2007, 7(4):266-281.

5. Franchini G, Ambinder RF, Barry M: Viral Disease in Hematology. Hematology Am Soc Hematol Educ Program 2000:409-423.

6. Murphy EL, Hanchard B, Figueroa JP, Gibbs WN, Lofters WS, Campbell M, Goedert JJ, Blattner WA: Modelling the risk of adult T-cell leukemia/lymphoma in persons infected with human T-lymphotropic virus type I. Int J Cancer 1989, 43(2):250-253.

7. Yamaguchi K, Watanabe T: Human T lymphotropic virus type-I and adult T-cell leukemia in Japan. Int J Hematol 2002, 76 Suppl 2:240-245.

8. Matsuoka M, Jeang KT: Human T-cell leukaemia virus type 1 (HTLV-1) infectivity and cellular transformation. Nat Rev Cancer 2007, 7(4):270-280.

9. Yoshida M, Seiki M, Yamaguchi K, Takatsuki K: Monoclonal integration of human T-cell leukemia provirus in all primary tumors of adult $\mathrm{T}$-cell leukemia suggests causative role of human $T$-cell leukemia virus in the disease. Proc Natl Acad Sci U S A 1984, 81(8):2534-2537.

10. Takeda S, Maeda M, Morikawa S, Taniguchi Y, Yasunaga J, Nosaka K, Tanaka Y, Matsuoka M: Genetic and epigenetic inactivation of tax gene in adult T-cell leukemia cells. Int J Cancer 2004, 109(4):559-567.

11. Mesnard JM, Barbeau B, Devaux C: HBZ, a new important player in the mystery of adult T-cell leukemia. Blood 2006, 108(13):3979-3982.

12. Nagata Y, Kontani K, Enami T, Kataoka K, Ishii R, Totoki Y, Kataoka TR, Hirata M, Aoki K, Nakano K et al: Variegated RHOA mutations in adult Tcell leukemia/lymphoma. Blood 2016, 127(5):596-604.

13. Etoh K, Yamaguchi K, Tokudome S, Watanabe T, Okayama A, Stuver S, Mueller N, Takatsuki K, Matsuoka M: Rapid quantification of HTLV-I provirus load: detection of monoclonal proliferation of HTLV-I-infected cells among blood donors. Int J Cancer 1999, 81(6):859-864.

14. Ohshima K, Mukai Y, Shiraki H, Suzumiya J, Tashiro K, Kikuchi M: Clonal integration and expression of human T-cell lymphotropic virus type I in carriers detected by polymerase chain reaction and inverse PCR. Am J Hematol 1997, 54(4):306-312.

15. Furukawa Y, Fujisawa J, Osame M, Toita M, Sonoda S, Kubota R, Ijichi S, Yoshida M: Frequent clonal proliferation of human T-cell leukemia virus type 1 (HTLV-1)-infected T cells in HTLV-1-associated myelopathy (HAMTSP). Blood 1992, 80(4):1012-1016.

16. Ikeda S, Momita S, Kinoshita K, Kamihira S, Moriuchi Y, Tsukasaki K, Ito M, Kanda T, Moriuchi R, Nakamura $T$ et al: Clinical course of human Tlymphotropic virus type I carriers with molecularly detectable monoclonal 
proliferation of $\mathbf{T}$ lymphocytes: defining a low- and high-risk population. Blood 1993, 82(7):2017-2024.

17. Carvalho EM, Da Fonseca Porto A: Epidemiological and clinical interaction between HTLV-1 and Strongyloides stercoralis. Parasite Immunol 2004, 26(11-12):487-497.

18. Bertone P, Stolc V, Royce TE, Rozowsky JS, Urban AE, Zhu X, Rinn JL, Tongprasit W, Samanta M, Weissman S et al: Global identification of human transcribed sequences with genome tiling arrays. Science 2004, 306(5705):2242-2246.

19. Esteller M: Non-coding RNAs in human disease. Nat Rev Genet 2011, 12(12):861-874.

20. Farazi TA, Juranek SA, Tuschl T: The growing catalog of small RNAs and their association with distinct Argonaute/Piwi family members. Development 2008, 135(7):1201-1214.

21. Mattick JS, Makunin IV: Non-coding RNA. Hum Mol Genet 2006, 15 Spec No 1:R17-29.

22. Li J, Wu B, Xu J, Liu C: Genome-wide identification and characterization of long intergenic non-coding RNAs in Ganoderma lucidum. PLoS One 2014, 9(6):e99442.

23. Cheng AM, Byrom MW, Shelton J, Ford LP: Antisense inhibition of human miRNAs and indications for an involvement of miRNA in cell growth and apoptosis. Nucleic Acids Res 2005, 33(4):1290-1297.

24. Vaz C, Ahmad HM, Sharma P, Gupta R, Kumar L, Kulshreshtha R, Bhattacharya A: Analysis of microRNA transcriptome by deep sequencing of small RNA libraries of peripheral blood. BMC Genomics 2010, 11:288.

25. Bandiera S, Hatem E, Lyonnet $S$, Henrion-Caude A: microRNAs in diseases: from candidate to modifier genes. Clin Genet 2010, 77(4):306-313.

26. Bueno MJ, Malumbres M: MicroRNAs and the cell cycle. Biochim Biophys Acta 2011, 1812(5):592-601.

27. Szulwach KE, Jin P, Alisch RS: Noncoding RNAs in mental retardation. Clin Genet 2009, 75(3):209-219.

28. Zhang B, Pan X, Cobb GP, Anderson TA: microRNAs as oncogenes and tumor suppressors. Dev Biol 2007, 302(1):1-12.

29. Shenouda SK, Alahari SK: MicroRNA function in cancer: oncogene or a tumor suppressor? Cancer Metastasis Rev 2009, 28(3-4):369-378.

30. Lu J, Getz G, Miska EA, Alvarez-Saavedra E, Lamb J, Peck D, SweetCordero A, Ebert BL, Mak RH, Ferrando AA et al: MicroRNA expression profiles classify human cancers. Nature 2005, 435(7043):834-838.

31. Huntzinger E, Izaurralde E: Gene silencing by microRNAs: contributions of translational repression and mRNA decay. Nat Rev Genet 2011, 12(2):99110.

32. Ruggero K, Corradin A, Zanovello P, Amadori A, Bronte V, Ciminale V, D'Agostino DM: Role of microRNAs in HTLV-1 infection and transformation. Mol Aspects Med 2010, 31(5):367-382.

33. Pichler K, Schneider G, Grassmann R: MicroRNA miR-146a and further oncogenesis-related cellular microRNAs are dysregulated in HTLV-1transformed T lymphocytes. Retrovirology 2008, 5:100.

34. Bellon M, Lepelletier Y, Hermine O, Nicot C: Deregulation of microRNA involved in hematopoiesis and the immune response in HTLV-I adult T-cell leukemia. Blood 2009, 113(20):4914-4917. 
35. Yeung ML, Yasunaga J, Bennasser Y, Dusetti N, Harris D, Ahmad N, Matsuoka M, Jeang KT: Roles for microRNAs, miR-93 and miR-130b, and tumor protein 53-induced nuclear protein 1 tumor suppressor in cell growth dysregulation by human T-cell lymphotrophic virus 1. Cancer Res 2008, 68(21):8976-8985.

36. Ruggero K, Guffanti A, Corradin A, Sharma VK, De Bellis G, Corti G, Grassi A, Zanovello P, Bronte V, Ciminale V et al: Small noncoding RNAs in cells transformed by human T-cell leukemia virus type 1: a role for a tRNA fragment as a primer for reverse transcriptase. $J$ Virol 2014, 88(7):3612-3622.

37. Heneine W, Khabbaz RF, Lal RB, Kaplan JE: Sensitive and specific polymerase chain reaction assays for diagnosis of human $T$-cell lymphotropic virus type I (HTLV-I) and HTLV-II infections in HTLV-I/IIseropositive individuals. J Clin Microbiol 1992, 30(6):1605-1607.

38. Pessoa R, Watanabe JT, Nukui Y, Pereira J, Casseb J, de Oliveira AC, Segurado AC, Sanabani SS: Molecular characterization of human T-cell lymphotropic virus type 1 full and partial genomes by Illumina massively parallel sequencing technology. PLoS One 2014, 9(3):e93374.

39. Shadrach B, Warshawsky I: A comparison of multiplex and monoplex Tcell receptor gamma PCR. Diagn Mol Pathol 2004, 13(3):127-134.

40. Clissa PB, Pessoa R, Ferraz KF, de Souza DR, Sanabani SS: Data on global expression of non-coding RNome in mice gastrocnemius muscle exposed to jararhagin, snake venom metalloproteinase. Data Brief 2016, 9:685-688.

41. Langenberger D, Bermudez-Santana CI, Stadler PF, Hoffmann S: Identification and classification of small RNAs in transcriptome sequence data. Pac Symp Biocomput 2010:80-87.

42. Schulze WX, Deng L, Mann M: Phosphotyrosine interactome of the ErbBreceptor kinase family. Mol Syst Biol 2005, 1:2005 0008.

43. Vlachos IS, Zagganas K, Paraskevopoulou MD, Georgakilas G, Karagkouni D, Vergoulis T, Dalamagas T, Hatzigeorgiou AG: DIANA-miRPath v3.0: deciphering microRNA function with experimental support. Nucleic Acids Res 2015, 43(W1):W460-466.

44. Calin GA, Sevignani C, Dumitru CD, Hyslop T, Noch E, Yendamuri S, Shimizu M, Rattan S, Bullrich F, Negrini M et al: Human microRNA genes are frequently located at fragile sites and genomic regions involved in cancers. Proc Natl Acad Sci U S A 2004, 101(9):2999-3004.

45. Yekta S, Shih IH, Bartel DP: MicroRNA-directed cleavage of HOXB8 mRNA. Science 2004, 304(5670):594-596.

46. Wynter CV: The dialectics of cancer: A theory of the initiation and development of cancer through errors in RNAi. Med Hypotheses 2006, 66(3):612-635.

47. Luthra R, Singh RR, Luthra MG, Li YX, Hannah C, Romans AM, Barkoh BA, Chen SS, Ensor J, Maru DM et al: MicroRNA-196a targets annexin A1: a microRNA-mediated mechanism of annexin A1 downregulation in cancers. Oncogene 2008, 27(52):6667-6678.

48. Szafranska AE, Doleshal M, Edmunds HS, Gordon S, Luttges J, Munding JB, Barth RJ, Jr., Gutmann EJ, Suriawinata AA, Marc Pipas J et al: Analysis of microRNAs in pancreatic fine-needle aspirates can classify benign and malignant tissues. Clin Chem 2008, 54(10):1716-1724. 
49. Maru DM, Singh RR, Hannah C, Albarracin CT, Li YX, Abraham R, Romans AM, Yao H, Luthra MG, Anandasabapathy $S$ et al: MicroRNA196a is a potential marker of progression during Barrett's metaplasiadysplasia-invasive adenocarcinoma sequence in esophagus. Am J Pathol 2009, 174(5):1940-1948.

50. Li Y, Zhang M, Chen H, Dong Z, Ganapathy V, Thangaraju M, Huang S: Ratio of miR-196s to HOXC8 messenger RNA correlates with breast cancer cell migration and metastasis. Cancer Res 2010, 70(20):7894-7904.

51. Chen C, Zhang Y, Zhang L, Weakley SM, Yao Q: MicroRNA-196: critical roles and clinical applications in development and cancer. J Cell Mol Med 2011, 15(1):14-23.

52. Hou W, Tian Q, Zheng J, Bonkovsky HL: MicroRNA-196 represses Bach1 protein and hepatitis $C$ virus gene expression in human hepatoma cells expressing hepatitis $C$ viral proteins. Hepatology 2010, 51(5):1494-1504.

53. Liu B, Xiang Y, Zhang HS: Circulating microRNA-196a as a candidate diagnostic biomarker for chronic hepatitis C. Mol Med Rep 2015, 12(1):105110.

54. Coskun E, von der Heide EK, Schlee C, Kuhnl A, Gokbuget N, Hoelzer D, Hofmann WK, Thiel E, Baldus CD: The role of microRNA-196a and microRNA-196b as ERG regulators in acute myeloid leukemia and acute $T$ lymphoblastic leukemia. Leuk Res 2011, 35(2):208-213.

55. Baldus CD, Burmeister T, Martus $P$, Schwartz S, Gokbuget N, Bloomfield CD, Hoelzer D, Thiel E, Hofmann WK: High expression of the ETS transcription factor ERG predicts adverse outcome in acute Tlymphoblastic leukemia in adults. J Clin Oncol 2006, 24(29):4714-4720.

56. Loughran SJ, Kruse EA, Hacking DF, de Graaf CA, Hyland CD, Willson TA, Henley KJ, Ellis S, Voss AK, Metcalf D et al: The transcription factor Erg is essential for definitive hematopoiesis and the function of adult hematopoietic stem cells. Nat Immunol 2008, 9(7):810-819.

57. Mitchelson KR, Qin WY: Roles of the canonical myomiRs miR-1, -133 and -206 in cell development and disease. World J Biol Chem 2015, 6(3):162-208.

58. Jackson AC: Rabies. Neurol Clin 2008, 26(3):717-726, ix.

59. Samir M, Vaas LA, Pessler F: MicroRNAs in the Host Response to Viral Infections of Veterinary Importance. Front Vet Sci 2016, 3:86.

60. Castillo JA, Castrillon JC, Diosa-Toro M, Betancur JG, St Laurent G, 3rd, Smit JM, Urcuqui-Inchima S: Complex interaction between dengue virus replication and expression of miRNA-133a. BMC Infect Dis 2016, 16:29.

61. Miles GD, Seiler M, Rodriguez L, Rajagopal G, Bhanot G: Identifying microRNA/mRNA dysregulations in ovarian cancer. BMC Res Notes 2012, 5:164.

62. Tao J, Wu D, Xu B, Qian W, Li P, Lu Q, Yin C, Zhang W: microRNA-133 inhibits cell proliferation, migration and invasion in prostate cancer cells by targeting the epidermal growth factor receptor. Oncol Rep 2012, 27(6):1967-1975.

63. Yamasaki T, Yoshino H, Enokida H, Hidaka H, Chiyomaru T, Nohata N, Kinoshita T, Fuse M, Seki N, Nakagawa M: Novel molecular targets regulated by tumor suppressors microRNA-1 and microRNA-133a in bladder cancer. Int J Oncol 2012, 40(6):1821-1830. 
64. Nohata N, Hanazawa T, Enokida H, Seki N: microRNA-1/133a and microRNA-206/133b clusters: dysregulation and functional roles in human cancers. Oncotarget 2012, 3(1):9-21.

65. Kress AK, Kalmer M, Rowan AG, Grassmann R, Fleckenstein B: The tumor marker Fascin is strongly induced by the Tax oncoprotein of HTLV1 through NF-kappaB signals. Blood 2011, 117(13):3609-3612.

66. Wu ZS, Wang CQ, Xiang R, Liu X, Ye S, Yang XQ, Zhang GH, Xu XC, Zhu T, Wu Q: Loss of miR-133a expression associated with poor survival of breast cancer and restoration of miR-133a expression inhibited breast cancer cell growth and invasion. BMC Cancer 2012, 12:51.

67. Ladd AN, Nguyen NH, Malhotra K, Cooper TA: CELF6, a member of the CELF family of RNA-binding proteins, regulates muscle-specific splicing enhancer-dependent alternative splicing. J Biol Chem 2004, 279(17):1775617764.

68. Hwang SJ, Yang Q, Meigs JB, Pearce EN, Fox CS: A genome-wide association for kidney function and endocrine-related traits in the NHLBI's Framingham Heart Study. BMC Med Genet 2007, 8 Suppl 1:S10.

69. Fox CS, Heard-Costa N, Cupples LA, Dupuis J, Vasan RS, Atwood LD: Genome-wide association to body mass index and waist circumference: the Framingham Heart Study 100K project. BMC Med Genet 2007, 8 Suppl 1:S18.

70. Mueller SB, Arora S, Mattocks N, Gurley SB, Kontos CD: Caskin2 is a novel regulator of endothelial cell quiescence. Arterioscl Throm Vas 2014, 34: A14.

71. Hakata $Y$, Umemoto T, Matsushita S, Shida H: Involvement of human CRM1 (exportin 1) in the export and multimerization of the Rex protein of human T-cell leukemia virus type 1. J Virol 1998, 72(8):6602-6607.

72. Hakata Y, Yamada M, Shida H: Rat CRM1 is responsible for the poor activity of human T-cell leukemia virus type 1 Rex protein in rat cells. $J$ Virol 2001, 75(23):11515-11525.

73. Peng Y, Li M, Clarkson BD, Pehar M, Lao PJ, Hillmer AT, Barnhart TE, Christian BT, Mitchell HA, Bendlin BB et al: Deficient import of acetylCoA into the ER lumen causes neurodegeneration and propensity to infections, inflammation, and cancer. $J$ Neurosci 2014, 34(20):6772-6789.

74. Goldstein JL, Anderson RG, Brown MS: Coated pits, coated vesicles, and receptor-mediated endocytosis. Nature 1979, 279(5715):679-685.

75. Schmid SL: Clathrin-coated vesicle formation and protein sorting: an integrated process. Annu Rev Biochem 1997, 66:511-548.

76. Molloy SS, Anderson ED, Jean F, Thomas G: Bi-cycling the furin pathway: from TGN localization to pathogen activation and embryogenesis. Trends Cell Biol 1999, 9(1):28-35.

77. Ohno H: Clathrin-associated adaptor protein complexes. J Cell Sci 2006, 119(Pt 18):3719-3721.

78. Batonick M, Favre M, Boge M, Spearman $P$, Honing S, Thali $M$ : Interaction of HIV-1 Gag with the clathrin-associated adaptor AP-2. Virology 2005, 342(2):190-200.

79. Dong X, Li H, Derdowski A, Ding L, Burnett A, Chen X, Peters TR, Dermody TS, Woodruff E, Wang JJ et al: AP-3 directs the intracellular trafficking of HIV-1 Gag and plays a key role in particle assembly. Cell 2005, $120(5)$ :663-674. 
80. Camus G, Segura-Morales C, Molle D, Lopez-Verges S, Begon-Pescia C, Cazevieille C, Schu P, Bertrand E, Berlioz-Torrent C, Basyuk E: The clathrin adaptor complex AP-1 binds HIV-1 and MLV Gag and facilitates their budding. Mol Biol Cell 2007, 18(8):3193-3203.

81. Chikatsu N, Kojima H, Suzukawa K, Shinagawa A, Nagasawa T, Ozawa H, Yamashita Y, Mori N: ALK+, CD30-, CD20- large B-cell lymphoma containing anaplastic lymphoma kinase (ALK) fused to clathrin heavy chain gene (CLTC). Mod Pathol 2003, 16(8):828-832.

82. Bridge JA, Kanamori M, Ma Z, Pickering D, Hill DA, Lydiatt W, Lui MY, Colleoni GW, Antonescu CR, Ladanyi M et al: Fusion of the ALK gene to the clathrin heavy chain gene, CLTC, in inflammatory myofibroblastic tumor. Am J Pathol 2001, 159(2):411-415.

83. Lau ST, Zhou T, Liu JA, Fung EY, Che CM, Lang BH, Ngan ES: Dysregulation of clathrin promotes thyroid cell growth and contributes to multinodular goiter pathogenesis. Biochim Biophys Acta 2015, 1852(8):16761686.

84. Cai X, Srivastava S, Sun Y, Li Z, Wu H, Zuvela-Jelaska L, Li J, Salamon RS, Backer JM, Skolnik EY: Tripartite motif containing protein 27 negatively regulates $\mathrm{CD} 4 \mathrm{~T}$ cells by ubiquitinating and inhibiting the class II PI3K-C2beta. Proc Natl Acad Sci U S A 2011, 108(50):20072-20077.

85. Yamagishi M, Nakano K, Miyake A, Yamochi T, Kagami Y, Tsutsumi A, Matsuda Y, Sato-Otsubo A, Muto S, Utsunomiya A et al: Polycombmediated loss of miR-31 activates NIK-dependent NF-kappaB pathway in adult $T$ cell leukemia and other cancers. Cancer Cell 2012, 21(1):121-135. 


\section{Figure captions}

1- Distribution of the total small RNAs on two representative samples. The clean reads were annotated as tRNAs, rRNAs, snoRNAs, snRNAs, scRNA miRNAs, intro, and others based on the Rfam database

2- Hierarchical cluster analysis of the 52 known small RNAs differentially expressed comparing ASM vs ASP samples. Rows of the heatmap represent the 52 small RNAs, columns correspond to samples. The cells are colored based on the deviance of the small RNAs expression in the sample from the average expression of the small RNAs, therefore red and blue cells represent respectively expression values higher or lower than mean expression across all samples (white) with color intensity proportional to the difference from the mean, in the regularized logarithmic scale. For clarity purposes, only a subimage of the heatmap has been shown in details.

3- Hierarchical cluster analysis of miRNAs differentially expressed comparing ASM vs ASP samples. Hierarchical clusters were generated using the Euclidean distance and Pearson correlations of miRNA expression patterns. The up- (red) and down-regulated (blue) miRNAs were scaled according to the depicted color code. 


\section{Supporting Information}

Table S1: Distribution of the small RNA massively sequencuing reads according to the chromosomes

Table S2: A full list of all known small RNAs identified in this study

Table S3: A full list of all novel small RNAs identified in this study

Table S4: List of small RNAs differentially expressed in asymptomatic HTLV-1 infected subjects with monoclonal (ASM) vs subjects with polyclonal T cell expansion (ASP)

Table S5: List of the potential protein targets for the deferentialy expressed miRNA in the ASM group 
Table 1. Demographic and clinical characteristics of HTLV-1 infected asymptomatic carriers subjected to small RNA analysis

\begin{tabular}{ccccccc}
\hline Sample & Sex & Age & Clonality featuers & Proviral load (copies/1000 PBMCs) & Total input reads & Total filtered reads (\%) \\
\hline 131 & Female & 52 & Polyclonal & 17 & $3,944,199$ & $165,061(4,18 \%)$ \\
146 & Female & 59 & Polyclonal & 208 & $12,538,011$ & $502,457(4,01 \%)$ \\
151 & Female & 72 & Polyclonal & 1 & $11,568,287$ & $389,210(3,36 \%)$ \\
152 & Female & 34 & Polyclonal & 60 & $6,323,875$ & $479,958(7,59 \%)$ \\
167 & Female & 58 & Polyclonal & 32 & $5,828,992$ & $469,333(8,05 \%)$ \\
172 & Female & 31 & Polyclonal & 102 & $4,307,133$ & $314,845(7,31 \%)$ \\
182 & Female & 80 & Polyclonal & 22 & $7,195,318$ & $350,231(4,87 \%)$ \\
188 & Female & 49 & Polyclonal & 8 & $8,913,900$ & $314,436(3,53 \%)$ \\
54 & Female & 42 & Monoclonal & ND & $6,452,823$ & $54,089(0,84 \%)$ \\
75 & Female & 45 & Monoclonal & ND & $11,154,254$ & $70,707(0,63 \%)$ \\
124 & Male & 70 & Monoclonal & 327 & $8,113,493$ & $142,191(1,75 \%)$ \\
143 & Female & 65 & Monoclonal & 71 & $5,719,645$ & $246,809(4,32 \%)$ \\
154 & Female & 28 & Monoclonal & 163 & $11,018,111$ & $425,570(3,86 \%)$ \\
200 & Female & 74 & Monoclonal & ND & $7,918,316$ & $409,349(5,17 \%)$ \\
212 & Male & 61 & Monoclonal & 27 & $12,777,420$ & $417,351(3,27 \%)$ \\
\hline
\end{tabular}


Table 2. List of miRNAs differentially expressed in asymptomatic HTLV-1 subjects with monoclonal (ASM) vs subjects with polyclonal T cell expansion (ASP)

\begin{tabular}{|c|c|c|c|c|c|c|c|}
\hline Gene ID & $\begin{array}{l}\text { FC ([ASM] } \\
\text { vs [ASP]) }\end{array}$ & $\begin{array}{c}\text { Log FC } \\
\text { ([ASM] vs } \\
\text { [ASP]) }\end{array}$ & $\begin{array}{c}\mathrm{FC} \text { (abs) } \\
\text { ([ASM] vs } \\
\text { [ASP]) }\end{array}$ & $\begin{array}{c}\text { Regulation ([ASM] } \\
\text { vs [ASP]) }\end{array}$ & Accession & Entrez ID & DB Refs \\
\hline MI0000450_1 & -4.05 & -2.02 & 4.05 & down & hsa-miR-133a & 406922 & miRBase:MI0000450 \\
\hline MI0003196_1 & -3.05 & -1.61 & 3.05 & down & hsa-miR-509-3p & 574514 & miRBase:MI0003196 \\
\hline MI0003639_2 & -2.87 & -1.52 & 2.87 & down & hsa-miR-625-3p & 693210 & miRBase:MI0003639 \\
\hline MI0014136_2 & -2.86 & -1.52 & 2.86 & down & hsa-miR-3120-3p & 100422882 & miRBase:MI0014136 \\
\hline MI0000088_2 & -2.80 & -1.48 & 2.80 & down & hsa-miR-30a-5p & 407029 & miRBase:MI0000088 \\
\hline MI0000750_1 & -2.74 & -1.46 & 2.74 & down & hsa-miR-26a-2-3p & 407016 & miRBase:MI0000750 \\
\hline MI0000091_1 & -2.38 & -1.25 & 2.38 & down & hsa-miR-33a-5p & 407039 & miRBase:MI0000091 \\
\hline MI0000743_1 & -2.14 & -1.10 & 2.14 & down & hsa-miR-34c-5p & 407042 & miRBase:MI0000743 \\
\hline MI0000784_2 & -2.13 & -1.09 & 2.13 & down & hsa-miR-376a-3p & 494325 & miRBase:MI0000784 \\
\hline MI0003677_1 & -2.04 & -1.03 & 2.04 & down & hsa-miR-655 & 724025 & miRBase:MI0003677 \\
\hline MI0000811_2 & -2.00 & -1.00 & 2.00 & down & hsa-miR-148b-3p & 442892 & miRBase:MI0000811 \\
\hline MI0005543_2 & 2.02 & 1.01 & 2.02 & up & hsa-miR-708-5p & 100126333 & miRBase:MI0005543 \\
\hline MI0000076_2 & 2.12 & 1.09 & 2.12 & up & hsa-miR-20a-3p & 406982 & miRBase:MI0000076 \\
\hline MI0015995_2 & 2.13 & 1.09 & 2.13 & up & hsa-miR-3605-5p & 100500853 & miRBase:MI0015995 \\
\hline MI0016775_1 & 2.15 & 1.10 & 2.15 & up & hsa-miR-4435 & 100616499 & miRBase:MI0016775 \\
\hline MI0003814_1 & 2.17 & 1.12 & 2.17 & up & hsa-miR-1271-5p & 100302203 & miRBase:MI0003814 \\
\hline MI0001735_1 & 2.18 & 1.12 & 2.18 & up & hsa-miR-409-5p & 574413 & miRBase:MI0001735 \\
\hline MI0016777_1 & 2.18 & 1.12 & 2.18 & up & hsa-miR-4435 & 100616341 & miRBase:MI0016777 \\
\hline MI0003676_1 & 2.24 & 1.16 & 2.24 & up & hsa-miR-654-5p & 724024 & miRBase:MI0003676 \\
\hline MI0003186_2 & 2.45 & 1.29 & 2.45 & up & hsa-miR-502-3p & 574504 & miRBase:MI0003186 \\
\hline MI0000105_2 & 2.56 & 1.36 & 2.56 & up & hsa-miR-29b-1-5p & 407024 & miRBase:MI0000105|RFAM:RF00074 \\
\hline
\end{tabular}


Table 3. List of novel small RNAs differentially expressed in asymptomatic HTLV-1 infected subjects with monoclonal (ASM) vs subjects with polyclonal T cell expansion (ASP)

\begin{tabular}{|c|c|c|c|c|c|}
\hline Gene ID & FC ([ASM] vs [ASP]) & Log FC ([ASM] vs [ASP]) & FC (abs) ([ASM] vs [ASP]) & Regulation ([ASM] vs [ASP]) & Gene Type \\
\hline NEWGENE31 & 2.76 & 1.47 & 2.76 & up & Unknown \\
\hline NEWGENE465 & 2.42 & 1.27 & 2.42 & up & snoRNA \\
\hline NEWGENE24 & 2.38 & 1.25 & 2.38 & up & Unknown \\
\hline NEWGENE53 & 2.36 & 1.24 & 2.36 & up & Unknown \\
\hline NEWGENE75 & 2.34 & 1.22 & 2.34 & up & Unknown \\
\hline NEWGENE96 & 2.30 & 1.20 & 2.30 & up & Unknown \\
\hline NEWGENE38 & 2.30 & 1.20 & 2.30 & up & Unknown \\
\hline NEWGENE95 & 2.29 & 1.20 & 2.29 & up & Unknown \\
\hline NEWGENE467 & 2.29 & 1.19 & 2.29 & up & miRNA \\
\hline NEWGENE203 & 2.25 & 1.17 & 2.25 & up & snoRNA \\
\hline NEWGENE377 & 2.23 & 1.16 & 2.23 & up & snoRNA \\
\hline NEWGENE466 & 2.22 & 1.15 & 2.22 & up & tRNA \\
\hline NEWGENE332 & 2.12 & 1.09 & 2.12 & up & snoRNA \\
\hline NEWGENE48 & 2.02 & 1.02 & 2.02 & up & Unknown \\
\hline NEWGENE186 & -2.03 & -0.10 & 2.03 & down & snoRNA \\
\hline
\end{tabular}




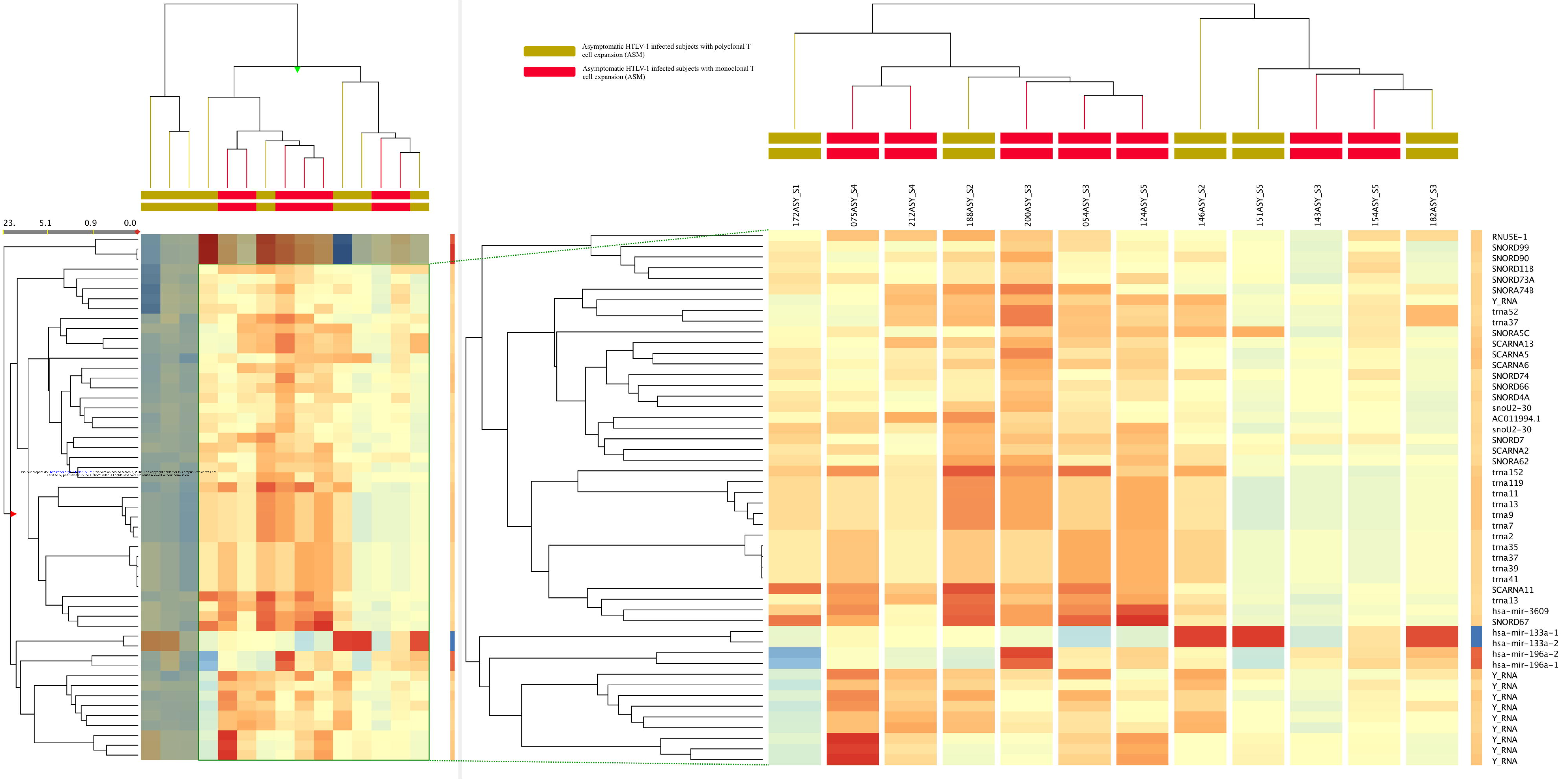




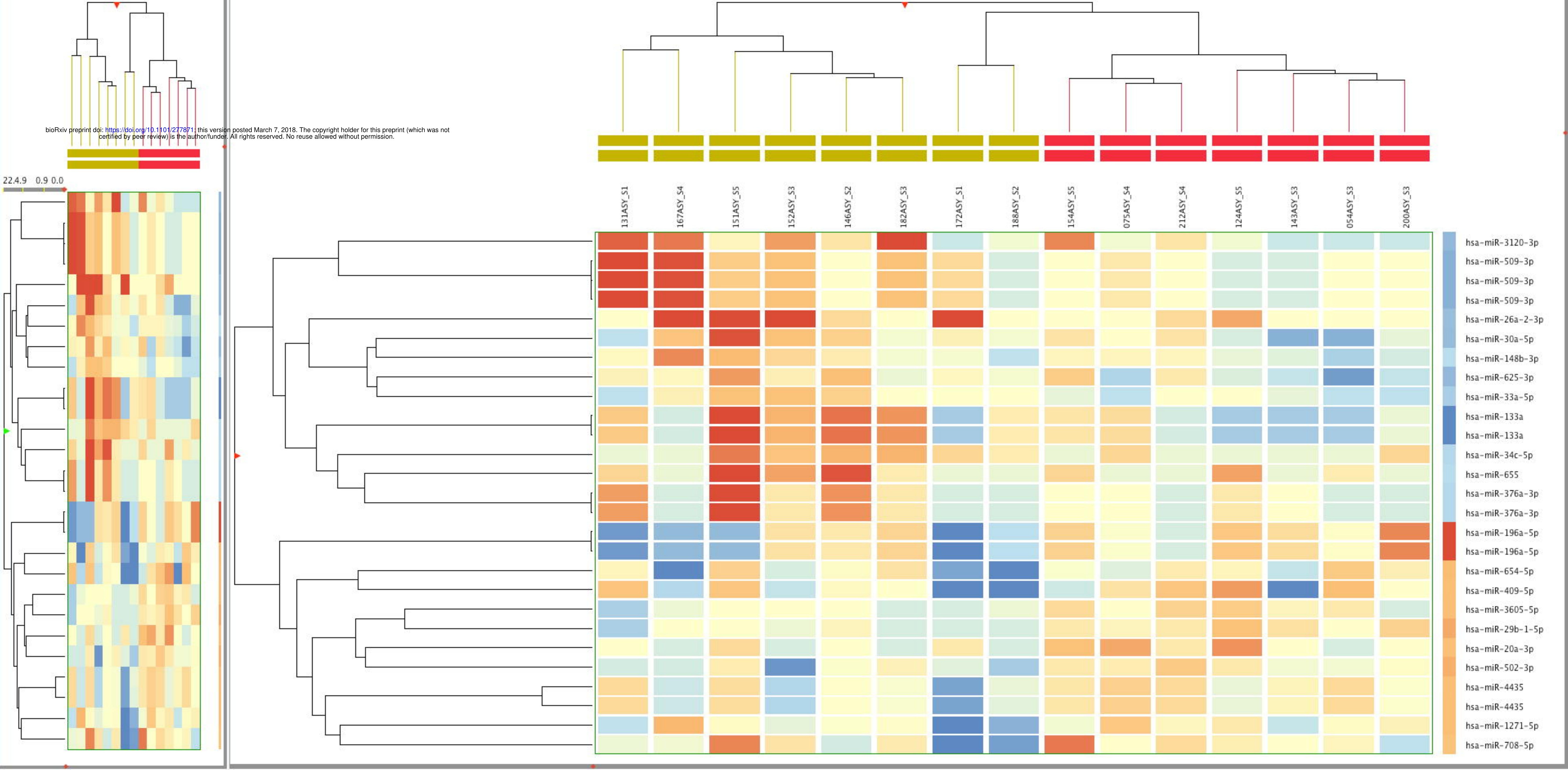

